\title{
CFD analysis of number of blades on the performance of counter rotating wind turbine designed using blade element momentum theory under transient condition
}

\author{
Didit Setyo Pamuji $1^{1, *}$, and Muhammad Agung Bramantya ${ }^{1}$ \\ ${ }^{1}$ Universitas Gadjah Mada, Department of Mechanical Engineering, Jl. Grafika No. 2 Kampus UGM, Yogyakarta 55281
}

\begin{abstract}
Unsteady CFD simulations on the effects of number of blades on counter rotating wind turbine (CRWT) were carried out in order to investigate the performance and the flow characteristics. In this paper, 2-bladed and 3-bladed CRWT were designed using Blade Element Momentum Theory (BEMT) which comprised of S833, S834, and S835 airfoils. As a comparison baseline, a SRWT model which have similar design with front rotor of the 3-bladed CRWT would be also investigated. It was found that the SRWT had the same rotational speed with the front rotor of the 3-bladed CRWT. There was about $10.24 \%$ and $11.79 \%$ rotational speed reduction of the rear rotor from the front rotor of 2-bladed CRWTs and 3-bladed CRWTs, respectively. Both of 2-bladed CRWT and 3-bladed CRWT have higher total power than SRWT, thereby generating more larger velocity deficits in the wake flow.
\end{abstract}

\section{Introduction}

Recently, horizontal axis wind-turbine (HAWT) is the leading type of wind electric power generation because of its easiness, reliableness, and durableness. By using single rotating wind turbine (SRWT), a mainstream design of HAWT have been used widely, a maximum coefficient of performance, $\mathrm{Cp}$, that could be reached are $59 \%$ (well known as Betz limit) with assumtions no viscous losses or wake swirl, and infinite number of blade [1]. The value would be less than $50 \%$ when these assumption are considered [2, 3]. It shows that the energy available from the oncoming wind flow are could not be harvested by more than $50 \%$ [4].

Nowadays, researchers found concept of dual rotating wind turbines (DRWTs) that could harnest additional power, therefore increase overall power production. Newman [5] studied multirotor turbines by expanding theory of Rankine-Froud momentum used to calculate Betz limit, and showed that DRWT with same diameter would have $\mathrm{Cp}$ up to $64 \%$, while adding number of rotors more than 2, would decrease the performance. Furthermore, a concept of counter-rotatig for DRWTs (rotors rotate in opposite direction) would give benefit for rear rotor because of additional kinetic energy related to swirling velocity of the wake flow behind the front rotor [4].

Many experimental as well as numerical studies related to performance improvement of CRWTs compare with SRWT have been studied. Some of field experiments, conducted by Appa [6] with $6 \mathrm{~kW}$ of 2bladed CRWTs and Jung [7] with $30 \mathrm{~kW}$ of 3-bladed CWRTs showed that the CRWTs harvested significant more power than conventional SRWT with the equal oncoming wind velocity. More recently, Ozbay [4] conducted wind tunnel experiment on wake characteristic and aeromechanic of small scaled DRWTs, and founded that DRWTs with counter-rotating rotors harvested more energy than co-ratating DRWTs and SRWT.

With an advanced of computational fluid dynamics, some numerical studies also have been studied comparing the performance of CRWTs to SRWT. Irawan et al [8] founded that CRWTs designed with close axial distance ranging 0.2 until 0.7 of the rotor diameter, produce higher mechanical power rather than longer axial distances. Buana et al [9] also founded that CRWTs with equal diameter size produce maximum mechanical power.

From the number of blades point of view, there were limited number of published paper which investigate the comparison on performance of number of blade for CRWTs comparably and comprehensively. Based on blade element momentum (BEM) theory, the different of number of blades would produce different airfoil chord length per section of blade, therefore generate different rotational speed both front rotor and rear rotor, then result different wake characteristic formed as well as different mechanical power produced.

By using transient CFD simulation of ANSYS Fluent, this paper aims to investigate the correlation of rotational speed generated both of front rotor and rear rotor from the velocity inlet specified, and then would also be calculated the mechanical power produced as well as the wake characteristic formed using steady simulation.

\footnotetext{
*orresponding author: didit.setyo.p@mail.ugm.ac.id
} 


\section{Methodology}

\subsection{Rotor design using blade element momentum method}

In order to design a blade of rotor using the blade element momentum (BEM) method, a simple formulation to calculate blade setting angle $\beta(r)$ and chord length as function of radius $c(r)$ is presented in Eq. (1) and Eq. (2) respectively [10, 11]. Several variables need to be determined first, they are number of blades (B), blade radius (R), tip speed ratio at the design point $\left(\lambda_{\mathrm{D}}\right)$, design lift coefficient of the airfoil $\left(\mathrm{C}_{\mathrm{LD}}\right)$, angle of attack of the airfoil lift $(\alpha)$ [10]. The present study uses NREL airfoil shape of S835 (root), S833 (main), and S833 (tip) [12].

$$
\begin{gathered}
\beta(r)=2 / 3 \arctan \left(R / r \lambda_{D}\right)-\alpha \\
c(r)=\left(16 \pi / B \mathrm{C}_{\mathrm{LD}}\right) \sin ^{2}\left[1 / 3 \arctan \left(R / r \lambda_{D}\right)\right]
\end{gathered}
$$

At the design step, the oncoming wind velocity was assumed $4.5 \mathrm{~m} / \mathrm{s}$, with design of tip speed ratio at 5 , blade radius $1.5 \mathrm{~m}$ (later scaled down with ratio $1 / 15$, in order to be validated in small wind tunnel) and angle of attacks corresponded with maximum lift coefficients of the three types airfoil were gotten from airfoil tools [13] at 50000 reynolds number. With the difference of number of blade, which are 2-bladed and 3-bladed, would produce different geometrical blade section as shown in Table 1.

Table 1. Optimed design geometry based BEM.

\begin{tabular}{|c|c|c|c|c|c|}
\hline \multicolumn{2}{|c|}{$\begin{array}{c}\text { Optimized } \\
\text { Geometry }\end{array}$} & $\begin{array}{c}\text { S835 } \\
\text { (root) }\end{array}$ & $\begin{array}{c}\text { S833 } \\
\text { (main) }\end{array}$ & \multicolumn{2}{c|}{ S834 (tip) } \\
\hline \multicolumn{2}{|c|}{$r / R$} & 0.2 & 0.4 & 0.85 & 1 \\
\hline \multicolumn{2}{|c|}{$\beta(r)$} & 19 & 8.21 & 0.38 & -0.96 \\
\hline 2-bladed & $c(r) / R$ & 0.347 & 0.253 & 0.139 & 0.119 \\
\hline 3-bladed & $c(r) / R$ & 0.232 & 0.168 & 0.092 & 0.079 \\
\hline
\end{tabular}

For the CRWT model, design of front rotor and rear rotor are identical, but the rear rotor were made by mirroring the airfoil configuration of the front rotor. As a result, the front rotor rotate in counter-clockwise direction while the rear rotor rotate in clockwise direction. The properties of the front rotor and rear rotor of both 2-bladed and 3-bladed CRWT are presented in Table 2.

Table 2. Properties of CRWT.

\begin{tabular}{|c|c|c|}
\hline Specification & Front Rotor & Rear Rotor \\
\hline Diameter $(\mathrm{mm})$ & 200 & 200 \\
\hline Position & Upwind & Downwind \\
\hline Blade material & PLA & PLA \\
\hline Rotation direction & $\begin{array}{c}\text { Counter- } \\
\text { Clockwise }\end{array}$ & Clockwise \\
\hline
\end{tabular}

Furthermore, as a comparison baseline, a SRWT model which have similar design with front rotor of the 3-bladed CRWT was also invstigated.

\subsection{Computational fluid dynamic of wind turbine}

CFD is a set of numerical solution for studying fluid dynamic problems based on the fundamental mass, momentum, and energy conservation principles. In the present study, CFD analysis of the CRWT only based on the conservation of mass and momentum principles with addition of shear-stress transport (SST) $k^{-} \omega$ turbulent modelling type that can be written respectively in Eq. (3), Eq (4), and Eq (5) [14].

$$
\begin{gathered}
\frac{\partial \rho}{\partial t}+\nabla \cdot(\rho \vec{v})=S m \\
\frac{\partial}{\partial t}(\rho \vec{v})+\nabla \cdot(\rho \vec{v} \vec{v})=-\nabla p+\nabla \cdot(\vec{\tau})+\rho \vec{g}+\vec{F}_{(4)} \\
\frac{\partial}{\partial t}(\rho k)+\frac{\partial}{\partial x_{i}}\left(\rho k u_{i}\right)=\frac{\partial}{\partial x_{j}}\left(\Gamma_{k} \frac{\partial k}{\partial x_{j}}\right)+G_{k}-Y_{k}+S_{k} \\
\frac{\partial}{\partial t}(\rho \omega)+\frac{\partial}{\partial x_{i}}\left(\rho \omega u_{i}\right)=\frac{\partial}{\partial x_{j}}\left(\Gamma_{k} \frac{\partial \omega}{\partial x_{j}}\right)+G_{\omega}-Y_{\omega}+S_{\omega}
\end{gathered}
$$

Where ${ }^{S m}$ is the mass source, $p$ is static pressure, ${ }^{\bar{\tau}}$ is stress tensor, $\rho \vec{g}$ is the gravity force, and $\vec{F}$ is other external body force. In the $k^{-}{ }^{\omega}$ turbulence models, $\mathrm{k}$ is the turbulent kinetic energy and ${ }^{\omega}$ is the dissipation rate of the turbulent kinetic energy.

This study use pressure-based solver approach in Fluent which mean the pressure field is obtained by solving pressure correction equation, results from combining conservation of mass and momentum equation. Velocity vector are corrected by the pressure to satisfy the continuity, and solve the turbulent model using the current value. The solution process involves iterations, wherein the entire set of governing equations are solved repeatedly until reach convergence [14].

\subsection{Simulation step and computational domain}

Actually, this simulation consist of two steps. In the beginning, transient simulation by activating dynamic mesh and one-degree of freedom rotation codes was performed for knowing the correlation of rotational speed both of front and rear rotor due to specified oncoming wind velocity. Then, steady simulations were conducted to know the torque from both rotor, therefore the mechanical power could be obtained by multiplying torque with rotational speed.

Blade rotor designed using BEM in the previous step played important role, because of the aerodynamic characteristic and inertia moments generated would affect the rotor rotational speed as well as the torque resulted.

In this study, the computational domain only consist of the rotor, with addition of rotating domain and farfiled domain, without including tower and ground. The overview of the volume grid generation are presented in Fig. 1. 

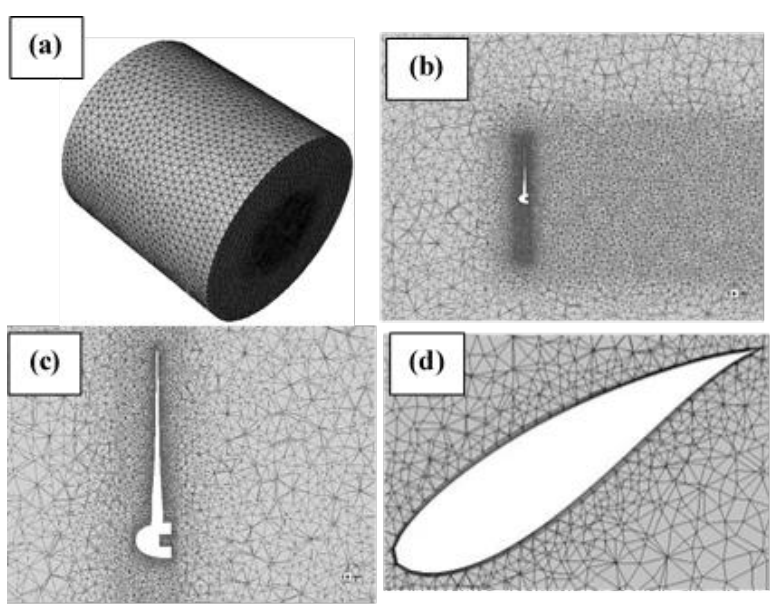

Fig. 1. Overview of the mesh (a) full domain, (b) side view, (c) zoom of side view, (d) mesh around airfoil.

The volume mesh generated was categorized as unstructured mesh by inserting layers on the surface of the rotor to accomodate boundary layer phenomena. The comparison of the volume mesh generated from the SRWT, 2-bladed CRWT, and 3-bladed CRWT are presented in Table 3.

Table 3. Volume mesh characteristic of the SRWT and CRWT.

\begin{tabular}{|c|c|c|c|}
\hline Variables & SRWT & 2-bladed & 3-bladed \\
\hline Meshing type & Tetrahedral & Tetrahedral & Tetrahedral \\
\hline $\begin{array}{c}\text { Element } \\
\text { number }\end{array}$ & $1,675,532$ & $1,474,734$ & $1,789,499$ \\
\hline $\begin{array}{c}\text { First layer } \\
\text { thickness }\end{array}$ & $\begin{array}{c}4 \mathrm{e}^{-5} \mathrm{~m} \\
\mathrm{y}+=0.8\end{array}$ & $\begin{array}{c}4 \mathrm{e}^{-5} \mathrm{~m} \\
\mathrm{y}+=0.8\end{array}$ & $\begin{array}{c}4 \mathrm{e}^{-5} \mathrm{~m} \\
\mathrm{y}+=0.8\end{array}$ \\
\hline $\begin{array}{c}\text { Average } \\
\text { skewness }\end{array}$ & 0,237 & 0.247 & 0.255 \\
\hline $\begin{array}{c}\text { Average } \\
\text { orthogonal } \\
\text { quality }\end{array}$ & 0,846 & 0.838 & 0.831 \\
\hline
\end{tabular}

\section{Results and discussion}

\subsection{Rotational speed driven from transient simulation}

The main result of the transient simulation in this study are characteristic of the rotor rotational speed, as given in Fig. 2. The SRWT, designed equally with the front rotor of 3-bladed CRWT, has similar rotational speed, as depicted by blue line (SRWT) which overlap the black line (front rotor of 3-bladed CRWT). They reach steady rotational speed after 30 seconds in approximately 2154 rpm. While the rear rotor of the 3-bladed CRWT achieve the steady rotational speed in $1900 \mathrm{rpm}$.

Furthermore, there were also founded a rotational speed drop of the rear rotor from the front rotor of 2bladed CRWT. In this 2-bladed CRWTs, the front rotor achieve steady rotational speed in approximately 2436.9 $\mathrm{rpm}$, while the rear rotor reachs $2188.32 \mathrm{rpm}$, which is higher than the back rotor of the 3-bladed CRWTs.

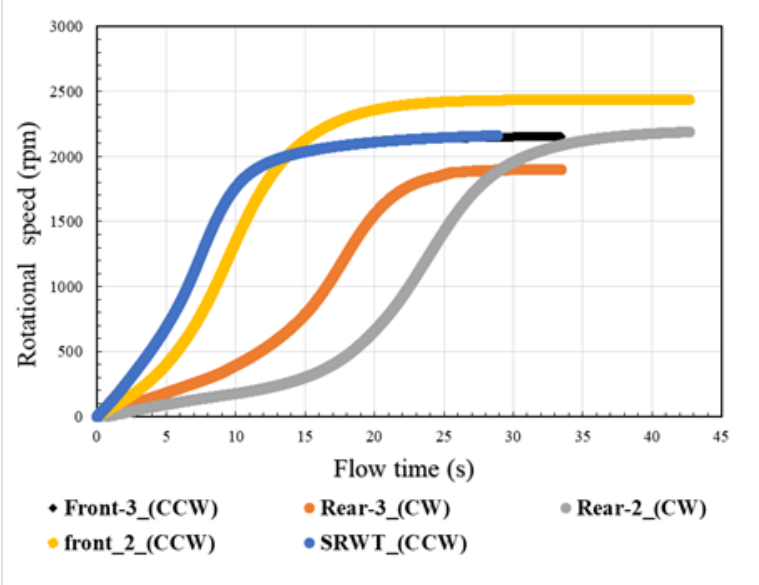

Fig. 2. Flow driven rotor rotational speed.

Those steady state rotational speed resulted in the transient simulation played important role for the next torque calculation in steady multiple rotating frames simulation. Mostly in the previous CRWT numerical study, researcher only use steady simulation method by assuming the rotational speed both of front and rear rotor, but this transient simulation give advantage in the prediction of the characteristic of front and rear rotor rotational speed which approach the real phenomena of the CRWTs rotational speed.

\subsection{Torque and mechanical power results}

After obtaining the characteristic of rotational speed from the transient simulation both of SRWT and CRWT, then torque can be resulted in the multiple rotating frames steady simulation, and finally mechanical power can be calculated by multiplying the rotational speed and the torque. Fig. 3 gives the comparison results of the SRWT and CRWTs performance at the steady rotational speed and some rotational speed reductions as loadinglike. Both of 2-bladed CRWT and 3-bladed CRWT have higher total power (i.e the addition of front rotor and rear rotor) than SRWT. Furthermore, in the higher rotational speed reduction (i.e after $80 \mathrm{rpm}$ rotational speed reduction), 2-bladed CRWT performs better than 3bladed CRWT.

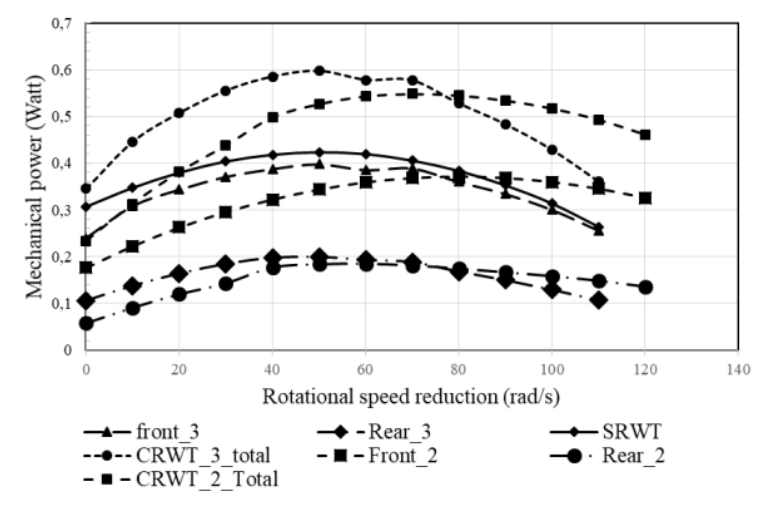

Fig. 3. Comparison of the SRWT and CRWTs performance. 


\subsection{Wake-flow characteristics behind the SRWT and CRWT}
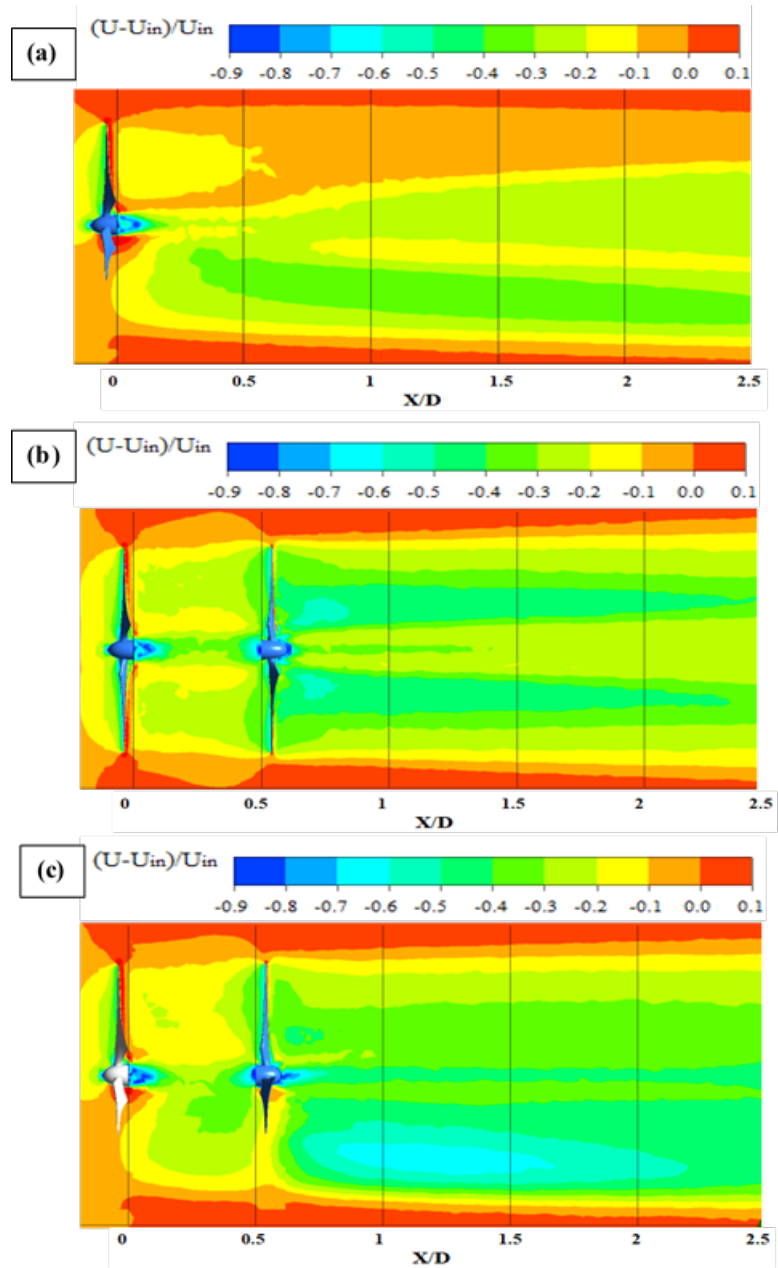

Fig. 4. Contour of velocity deficits of (a) SRWT, (b) 2-bladed CRWTs, (c) 3-bladed CRWTs.

Based on [15], there were some factors which greatly affected the characteristics of the near wake flow, like the presence of the rotor (i.e., the number of blades, blade aerodynamics, and tip vortices), and the interactions between the turbine rotors, tower and necelles. In this study, the oncoming airfow drive the rotor to rotate and convert a portion of the kinetic energy of them into torque. This phenomena cause decelaration of the airflow streams as they pass through the rotation disk-like of the rotor.

Fig. 4 gives velocity deficit in the wake behind the SRWT and CRWT models at their optimum power output (i.e. SRWT at $50 \mathrm{rad} / \mathrm{s}$ reduction, 2-bladed CRWTs at $70 \mathrm{rad} / \mathrm{s}$ reduction, and 3-bladed CRWTs at $50 \mathrm{rad} / \mathrm{s}$ reduction, from their steady rotational speed). By comparing the velocity deficit, both 2-bladed and 3bladed CRWT faced more velocity deficit than the SRWT which can be attributed by the presence of the rear rotor. From the mechnical power output, both CRWTs could harvest more power than SRWT from the same oncoming wind velocity, thereby generating more larger velocity deficits in the wake flow. It also can be seen that, the velocity deficits of the 3-bladed CRWT in comparison with 2-bladed CRWT were higher, so that 3bladed CRWT could generate more mechanical power.

\section{Conclusions}

A numerical study based on CFD analysis was carried out to investigate the performance and wake characteristics of 2-bladed CRWTs and 3-bladed CRWTs in comparison to those of a conventional SRWT. The transient simulation to drive rotational speed of the rotor was performed, followed by steady simulation to generate the torque, then finally could be calculated the mechanical power resulted.

By using multiple reference frames (MRF) simulation and assuming there are loading-like represented by rotational speed reduction from their steady rotational speed, it can be known that total mechanical power resulted from both CRWTs were higher than SRWT baseline. In more detail, after 70 $\mathrm{rad} / \mathrm{s}$ rotational speed reduction, it can be shown that 2bladed CRWTs could produce more total mechanical power than 3-bladed CRWTs. Later, the results can be used as consideration in choosing the siutable generator specification in term of torque and rotational speed requirements.

The authors thank the Indonesia Endowment Fund for Education (LPDP) for supporting this research and paper.

\section{References}

1. A. Betz, Schraubenpropeller mit Geringstem Energieverlust (Ship Propellers with Minimum Loss of Energy), Ph.D. thesis, University of G€ ottingen, G€ ottingen, Germany (1919)

2. V.L. Okulov, J.N. Sørensen, "Refined Betz Limit for Rotors With a Finite Number of Blades," Wind Energy, 11 (4), 415-426 (2008)

3. A. Sharma, A. Frere, Aerodynamic Efficiency Entitlement Study of a Horizontal Axis Wind Turbine, Internal Report, General Electric Global Research Center, Schenectady, NY. (2009)

4. A. Ozbay, T. Wei, H. Hui, Experimental investigation on the wake characteristics and aeromechanics of dual-rotor wind turbines, Journal of Engineering for Gas Turbines and Power 138 (4), (2016)

5. B.G., Newman, Multiple Actuator-Disk Theory for Wind Turbines, J. Wind Eng. Ind. Aerodyn, 24 (3), 215-225 (1986)

6. K. Appa, Counter Rotating Wind Turbine System, Technical Report, Energy Innovations Small Grant (EISG) Program, Sacramento, CA. (2002)

7. S.N. Jung, T.S. No, K.W. Ryu, Aerodynamic Performance Pre- diction of a $30 \mathrm{~kW}$ CounterRotating Wind Turbine System, Renewable Energy, 30 (5), 631-644 (2005)

8. Y.H. Irawan, M.A. Bramantya, Numerical simulation of the effect of axial distance between 
two rotors in counter-rotating wind turbines.

Proceedings - 2016 2nd International Conference on Science and Technology-Computer, ICST 2016, 3, 1-5 (2017)

9. S.W. Buana, V.A. Koehuan, A. Riszal, S. Kamal, Analisis pengaruh rasio diameter sebagai parameter kinerja aerodinamika dual rotor counter-rotating (2016)

10. S. Mathew, Wind Energy Fundamentals, Resource Analysis and Economics. (Heidelberg: Springer, 2006)

11. J. McCosker, Design and Optimization of a Small Wind Turbine (Hartford, Connecticut: Rensselaer Polytechnic Institute, 2012)

12. D.M. Somers, S833, S834, and S835 Airfoils: (2005). https://doi.org/10.2172/15020040

13. http://airfoiltools.com/

14. C.E. Carcangiu, CFD-RANS study of horizontal axis wind turbines (Diss. Universita'degli Studi di Cagliari, 2008)

15. L.J. Vermeer, J.N. Sørensen, A. Crespo, Wind turbine wake aerodynamics. Progress in aerospace sciences, 39, 6-7 (2003) 